\title{
Properties of Crude Campylobacter jejuni Heat-Labile Enterotoxin
}

\author{
FREDERICK A. KLIPSTEIN* AND RICHARD F. ENGERT \\ Department of Medicine, University of Rochester Medical Center, Rochester, New York 14642
}

Received 21 February 1984/Accepted 30 April 1984

\begin{abstract}
The amount of crude Campylobacter jejuni enterotoxin present in culture products was quantitated by comparing the response of these preparations with that of pure Escherichia coli heat-labile toxin (LT) in the Chinese hamster ovary assay and in enzyme-linked immunosorbent assays that used GM ganglioside or antisera to LT or both. Maximum $C$. jejuni enterotoxin production was achieved by growth at $42^{\circ} \mathrm{C}$ for $24 \mathrm{~h}$ under agitation in supplemented GC medium. Adding polymyxin separately to either the broth supernatant or the cells enhanced the recovery of toxin; the yield from cell lysates was much lower: The quantity of $C$. jejuni enterotoxin produced by clinical isolates obtained locally or provided from Mexico varied widely, over a spectrum from none to large amounts; quantitative values for the amount of $C$. jejuni enterotoxin determined by the Chinese hamster ovary and enzyme-linked immunosorbent assays correlated with the degree of secretory potency of this material in ligated rat ileal loops. The cytotonic activity of $C$. jejuni enterotoxin in Chinese hamster ovary cells was abolished by heating at $96^{\circ} \mathrm{C}$ for $10 \mathrm{~min}$ and by preincubation either with $\mathrm{GM}$ ganglioside or with LT or cholera toxin antisera. The secretory activity of $C$. jejuni enterotoxin in ligated rat ileal loops was passively neutralized by antiserum to LT, and immunizing rats with either LT or its B subunit significantly $(P<0.001)$ reduced fluid response to active challenge with $C$. jejuni enterotoxin in ligated ileal loops. These observations indicate that strains of $C$. jejuni vary in their capacity to elaborate a heat-labile enterotoxin that has close immunological homology with LT and cholera toxin.
\end{abstract}

Campylobacter jejuni is now recognized as a major worldwide cause of acute diarrhea among persons living in either temperate or tropical climates $(2,4,15,48)$ as well as among travelers $(38,42,47)$. Enteric infection with this organism is particularly prevalent in children $(6,35)$, among whom it appears to rank as the third most common cause of acute diarrhea, after rotavirus and enterotoxigenic Escherichia coli $(1,43)$, in developing countries $(3,5,13,18)$. A significant proportion of children living in these areas are also asymptomatic carriers of $C$. jejuni $(3,5,18,39)$.

Little is known about the pathophysiology of $C$. jejuni enteric infection. The organism can clearly be invasive, as shown by either overt colitis or the presence of blood and leukocytes in the stools of infected persons $(2,15,30)$ and by studies on experimentally contaminated animals (7). However, there is often only a secretory form of diarrhea, particularly in children $(2,18,35,42,48)$, suggesting that a different mechanism, such as an enterotoxin, may be involved. Enterotoxin production has not been detected by laboratories testing routinely grown $C$. jejuni cultures for toxin by the Chinese hamster ovary (CHO), Y1 adrenal cell tissue culture, and suckling mouse assays or by instillation into ligated intestinal loops of rabbits, calves, or piglets $(21,33,49)$. In contrast, Ruiz-Palacios and his colleagues in Mexico, using special culture conditions, have recently shown that many $C$. jejuni clinical isolates from children produce a heat-labile enterotoxin that raises intracellular cyclic AMP levels, causes cytotonic changes in CHO cells, and induces fluid secretion in ligated rat ileal loops; the secretory activity of this toxin is neutralized by antiserum to cholera toxin (CT) (41). Culture supernatants of these toxigenic strains have also been shown to cause intraluminal secretion of fluid and electrolytes when perfused in vivo through rat jejunal segments (16).

\footnotetext{
* Corresponding author.
}

In the present study, we quantitated the amount of $C$. jejuni enterotoxin (CJT) present in various growth products by comparing the response of these preparations with that of pure $E$. coli heat-labile enterotoxin (LT) in enzyme-linked immunosorbent assays (ELISAs) that used antiserum to LT and in the CHO tissue culture assay. This permitted us to identify the culture media, growth conditions, and procedures for processing growth products that gave maximum CJT production and recovery. The amount of CJT produced by strains of $C$. jejuni isolated from persons with acute diarrhea, both local Rochester, N.Y., residents and Mexicans, was determined quantitatively by the in vitro tests, and these results were compared with those for secretory activity in ligated rat ileal loops. The relationship between crude CJT and pure LT was further evaluated by determining the neutralizing capacity of antiserum to LT on the cytotonic activity of CJT in the CHO assay and on its secretory effect in ligated rat ileal loops and by determining the protective effect of immunizing rats with either LT or its B subunit against active challenge with CJT in ligated ileal loops.

\section{MATERIALS AND METHODS}

Bacterial strains. $C$. jejuni strains $\mathrm{C} 1$ to $\mathrm{C} 6$ were clinical isolates obtained consecutively from persons with acute diarrhea in Rochester; strains INN-1-79 and INN-73-83 were cultured from Mexican children with diarrhea and kindly provided by G. M. Ruiz-Palacios, Instituto Nacional de la Nutrición, Tlalpan, Mexico. Some of the enterotoxigenic properties of strain INN-1-79 have been described previously (41). As a routine precaution, multiple copies of each isolate were made and stored at $-60^{\circ} \mathrm{C}$ in brucella broth (Difco Laboratories, Detroit, Mich.) plus $15 \%$ glycerol upon receipt so that each isolate underwent no more than two passages before being tested.

Enterotoxin production. $C$. jejuni isolates were grown for $24 \mathrm{~h}$ on GC plates made from GC medium base (Difco) plus $0.1 \%$ IsoVitaleX (BBL Microbiology Systems, Cockeysville, Md.) at $42^{\circ} \mathrm{C}$ under reduced atmospheric conditions in 
a GasPak system (BBL Microbiology Systems) without a catalyst. Two growth media were compared: brucella broth, which was used by Ruiz-Palacios et al. (41), and GC medium, which is a highly enriched medium designed for the growth of fastidious organisms. Growth from each plate was harvested in $5 \mathrm{ml}$ of sterile saline, of which $4 \mathrm{ml} /$ liter of liquid medium was used to inoculate either brucella broth supplemented with $0.25 \%$ L-asparagine, L-serine, and L-glutamic acid as described previously (41) or GC medium without the agar base but with $0.1 \%$ IsoVitaleX. All liquid cultures were grown at $42^{\circ} \mathrm{C}$ in the presence of $8 \% \mathrm{CO}_{2}$.

All $C$. jejuni growth fractions were processed with equipment and membranes that had not previously been exposed to either LT or CT. After culture, the cells were centrifuged at $13,000 \times g$ for $10 \mathrm{~min}$ at $4^{\circ} \mathrm{C}$, and the supernatants were sterilized by passage through a $0.22-\mu \mathrm{m}$-pore-size membrane filter (Millipore Corp., Bedford, Mass.) and, except where specified, concentrated 10-fold on a YM-10 ultrafiltration membrane (Amicon, Corp., Danvers, Mass.). For polymyxintreated supernatants, $2 \mathrm{mg}$ of polymyxin B sulfate per $\mathrm{ml}$ of medium was added to the whole growth culture, which was then incubated for an additional $10 \mathrm{~min}$ at $42^{\circ} \mathrm{C}$ under agitation; the supernatant was then obtained by centrifugation.

Cells from cultures that had not been exposed to polymyxin were also processed. After separation, the cells were either treated with polymyxin or lysed by sonication. Cells treated with polymyxin were suspended in $50 \mathrm{ml}$ of $0.15 \mathrm{M}$ Tris buffer plus $0.9 \% \mathrm{NaCl}, \mathrm{pH} 6.6$, containing $2 \mathrm{mg}$ of polymyxin $\mathrm{B}$ sulfate per $\mathrm{ml}$ and incubated at $42^{\circ} \mathrm{C}$ under agitation for $10 \mathrm{~min}$; they were then removed by centrifugation, and the supernatant was filtered through a sterile membrane and concentrated to $5 \mathrm{ml}$ on a YM-10 ultrafiltration membrane. For lysis, the cells were suspended in $50 \mathrm{ml}$ of TEAN buffer (Tris, EDTA, sodium azide, $\mathrm{NaCl}$ ), frozen at $-60^{\circ} \mathrm{C}$ for $4 \mathrm{~h}$, thawed, and lysed on a model W140 Sonifer cell disrupter (Heat Systems Ultrasonics, Plainview, N.J.). The supernatant was then obtained by centrifugation, filtered through a sterile membrane, and concentrated to $5 \mathrm{ml}$ on a YM-10 ultrafiltration membrane.

The LT holotoxin was prepared in purified form by previously described methods (9) from $E$. coli PDF82, a transformed strain K-12 derivative bearing the LT gene(s) of the Ent plasmid from the human $E$. coli strain H10407 (11). The LT toxin B subunit was purified by chromatographic techniques (12) from $E$. coli PDF87, a transformed strain $\mathrm{K}-12$ derivative bearing the $\mathrm{B}$ subunit plasmid of the human $E$. coli strain $\mathrm{H} 10407$ (10). The amounts of LT and B subunit used were based on their protein concentration, determined by the method of Lowry et al. (32).

Enterotoxin assays. (i) $\mathrm{CHO}$ assay. The $\mathrm{CHO}$ assay was performed by a modification (8) of the techniques described by Guerrant et al. (20), except that 96-well microtiter plates (Costar, Inc., Cambridge, Mass.) were used. All samples were tested in duplicate with working volumes of $100 \mu \mathrm{l}$ per well. Morphological alteration (elongation) of more than $50 \%$ of the cells in a well was considered a positive response.

(ii) ELISAs. The techniques for raising antisera to LT in rabbits and goats and for performing double-sandwich ELISAs with these antisera have been described previously (27, 29). All the samples were tested in duplicate with working volumes of $200 \mu \mathrm{l}$ per well. Because pure GM1 ganglioside was unavailable for these studies, GM ganglioside (type III; Sigma Chemical Co., St. Louis, Mo.) was used in excess. In the GM/LT ELISA $50 \mu \mathrm{g}$ of GM ganglioside per $\mathrm{ml}$ was used for the solid phase, and in the LT/LT ELISA a 1:50 dilution of crude rabbit anti-LT antiserum was used for the solid phase; in both instances, a 1:500 dilution of crude goat antiLT antiserum was the second antibody, followed by a 1:400 dilution of alkaline phosphatase-conjugated rabbit anti-goat immunoglobulin $\mathrm{G}$ antiserum (Miles Laboratories, Inc., Elkhart, Ind.).

(iii) Ligated rat ileal loops. Toxin preparations in $250 \mu \mathrm{l}$ of buffer were placed for $16 \mathrm{~h}$ into single $10-\mathrm{cm}$-long ligated ileal loops of fasting Sprague-Dawley rats weighing 175 to $200 \mathrm{~g}$ as described previously (28). The results reported for each data point are the mean \pm the standard error of the mean for the volume/length ratio $(V / L)$ in four rats.

Immunization procedures. Rats were given primary immunization intraperitoneally with Freund complete adjuvant, followed by two boosters given perorally at 4-day intervals. Peroral immunization was given via intragastric tube $2 \mathrm{~h}$ after peroral administration of $50 \mathrm{mg}$ of cimetidine (Tagamet; Smith Kline \& French Laboratories, Carolina, P.R.) per kg of body weight to ablate gastric secretion. The dose of LT was $100 \mu \mathrm{g}$ intraperitoneally for primary immunization and $500 \mu \mathrm{g}$ for each peroral booster, and that of B subunit was $200 \mu \mathrm{g}$ intraperitoneally for primary immunization and 1,000 $\mu \mathrm{g}$ for each peroral booster. These immunization dosages were selected because they have previously been shown to provide a significant $(P<0.001)$ reduction in fluid secretion in immunized rats compared with unimmunized controls challenged by instilling either LT or viable LT-producing $E$. coli cells into ligated ileal loops (26). Control and immunized rats were challenged simultaneously as described above 4 to 6 days after the final booster immunization by instilling CJT into the ligated ileal loops. The significance of the difference in secretion between the immunized and control groups was determined by Student's $t$ test for two independent means.

\section{RESULTS}

Quantitation of CJT. To provide a uniform quantitative value for the amount of CJT produced by individual strains under different culture conditions and obtained by various recovery procedures, this value was expressed as the

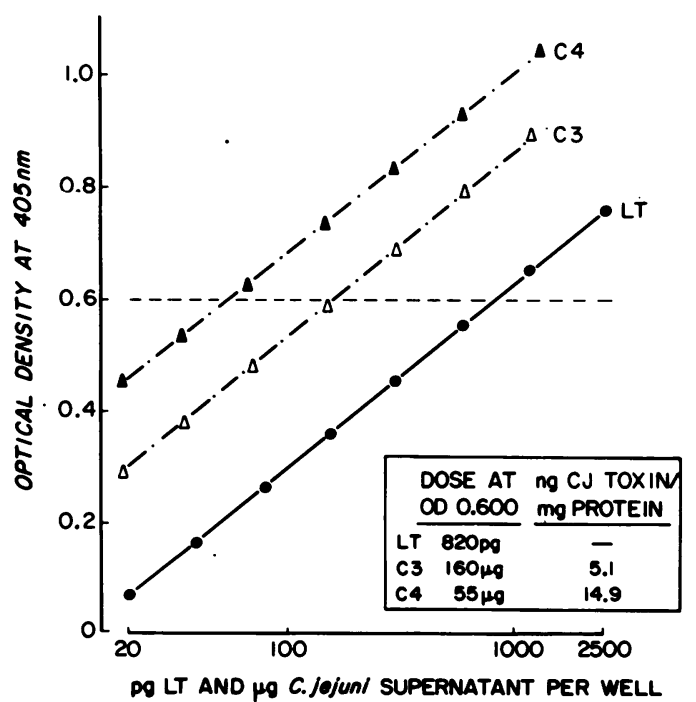

FIG. 1. Response to graded amounts of LT and concentrated broth supernatants of $C$. jejuni strains $\mathrm{C} 3$ and $C 4$ in the GM/LT ELISA. Comparison of the values for LT and the $C$. jejuni supernatants which gave an optical density of 0.600 at $405 \mathrm{~nm}$ gave the amount of CJT. 
amount of toxin present per milligram of total protein that was comparable to the activity of LT as determined in the $\mathrm{CHO}$ and ELISA assays. The effect of graded concentrations of pure LT (in picograms) and $C$. jejuni growth products (in micrograms) was determined in each of these assays, and the amount of each material that gave an optical density of 0.600 at $405 \mathrm{~nm}$ in the ELISAs (Fig. 1) and in the last positive well in the $\mathrm{CHO}$ assay was established. The amount of CJT (i.e., LT activity equivalent) present in the $C$. jejuni product was calculated by dividing the quantity of LT which gave this result by that of the $C$. jejuni product which gave the same result in that specific assay; this figure was multiplied by 1,000 to express the amount of CJT in nanograms per milligram of total protein of the culture product.

Toxin production and recovery. To determine the optimal growth media and culture conditions, 1-liter batches of $C$. jejuni INN-73-83 were grown for various periods with or without agitation in supplemented GC medium or in amino acid-supplemented brucella broth. Growth was monitored by measuring the optical density of the whole cultures at 650 $\mathrm{nm}$, and toxin production was measured by both GM/LT ELISA and CHO assays of polymyxin-treated culture supernatants. Bacterial growth was the same under stationary culture conditions, but toxin production was greater after $24 \mathrm{~h}$ in the GC medium (Fig. 2). Maximum growth and toxin production occurred after $24 \mathrm{~h}$ of growth under agitation in the GC medium.

Adding polymyxin to the whole broth culture for the final 10 min of incubation of a 24-h culture in GC medium grown under agitation approximately doubled the concentration of CJT per milligram of protein in the broth supernatant (Table 1). Precipitated cells from broth cultures (which had not been exposed to polymyxin) yielded approximately the same concentration of CJT as the polymyxin-treated broth supernatant did when the cells were resuspended and incubated with polymyxin for $10 \mathrm{~min}$; in contrast, sonicated cells released only a small amount of toxin per milligram of protein. To exclude the possibility that the low concentration of toxin obtained from the sonicated cells was the result of an inadequate cell mass, 10 liters of growth was processed similarly; this did not increase the concentration of toxin. Although the toxin concentration per milligram of protein was approximately the same in both polymyxin-treated broth supernatant and cell preparations, the total yield of

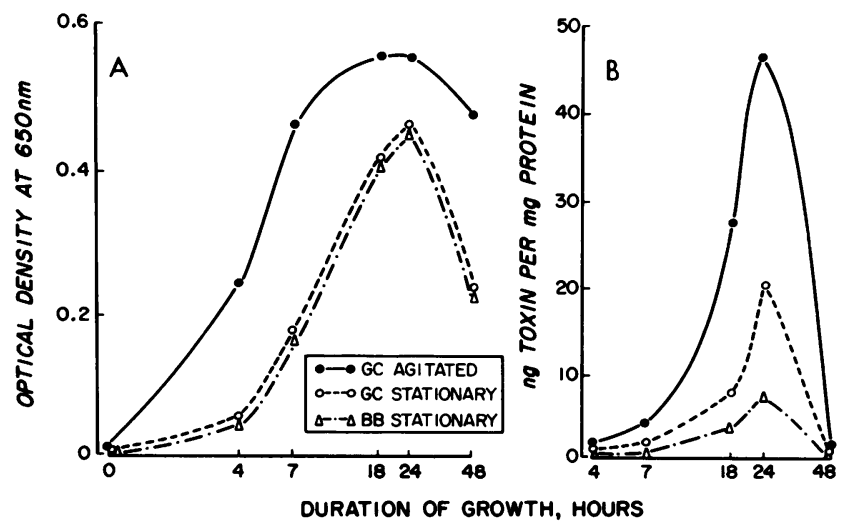

FIG. 2. Effect of different culture media and growth conditions on growth (A) and toxin production (B) by $C$. jejuni INN-73-83. BB, Brucella broth. Values for toxin production were determined by the CHO assay.
TABLE 1. Recovery of CJT from different growth fractions ${ }^{a}$

\begin{tabular}{lcccc}
\hline \multirow{2}{*}{ Assay } & \multicolumn{4}{c}{ CJT (ng/ml of total protein) recovered from: } \\
\cline { 2 - 5 } & $\begin{array}{c}\text { Super- } \\
\text { natant }\end{array}$ & $\begin{array}{c}\text { Super- } \\
\text { natant } \\
\text { with } \\
\text { PM }^{b}\end{array}$ & $\begin{array}{c}\text { Sonicated } \\
\text { cells }\end{array}$ & $\begin{array}{c}\text { Cells with } \\
\text { PM }\end{array}$ \\
\hline CHO & 14.6 & 29.1 & 0.9 & 38.6 \\
GM/LT ELISA & 20.0 & 50.6 & 2.5 & 47.6 \\
\hline
\end{tabular}

"Obtained from C. jejuni INN-73-83 grown under agitated conditions for 24 $h$ in supplemented GC medium.

${ }^{h}$ PM, Polymyxin.

toxin, expressed as micrograms of toxin per liter of cells, was considerably greater from the supernatant because of its greater amount of total protein. When measured by $\mathrm{CHO}$ assay, 1 liter of cells yielded a total of $81.8 \mu \mathrm{g}$ of toxin from the polymyxin-treated broth supernatant but only $4.1 \mu \mathrm{g}$ of toxin from the polymyxin-resuspended cells.

As a result of these tests, the CJT used in subsequent studies was derived from broth supernatants of polymyxintreated cultures grown for $24 \mathrm{~h}$ under agitation in supplemented GC medium.

Toxin production by clinical isolates. The amount of CJT produced, as determined by CHO and ELISA assays of 10fold-concentrated broth supernatants, varied from none to large amounts (Table 2). Preparations shown by these assays to produce moderate or large quantities of toxin also caused fluid secretion in ligated rat ileal loops. In each instance, heating the toxin preparations at $96^{\circ} \mathrm{C}$ for $10 \mathrm{~min}$ abolished their activity in the $\mathrm{CHO}$ cell assay and their secretory effect in ligated rat ileal loops. No relationship was apparent between the amount of bacterial growth, as measured by the optical density at $650 \mathrm{~nm}$, and toxin production for five strains, but the growth of one nontoxigenic strain was slight and that of the two strongest toxin producers was the greatest.

Detection of enterotoxigenic strains of $C$. jejuni by ELISA. To determine whether toxigenic strains of $C$. jejuni can be identified by ELISA of unconcentrated broth supernatants, these fractions of the eight clinical isolates were tested in both the LT/LT and GM/LT ELISAs. We have found in previous studies that unconcentrated broth supernatants of LT-producing enterotoxigenic $E$. coli strains always give an optical density of $>0.200$ in both of these ELISAs, whereas those of nontoxigenic strains consistently give values of $<0.200$ (29). Only the broth supernatants of the three strains

TABLE 2. CJT production by clinical isolates

\begin{tabular}{|c|c|c|c|c|c|}
\hline \multirow{3}{*}{$\begin{array}{l}\text { C. jejuni } \\
\text { isolate }\end{array}$} & \multirow{3}{*}{$\begin{array}{l}\text { Bacterial } \\
\text { growth } \\
\left(\mathrm{OD}_{650}\right)^{a}\end{array}$} & \multicolumn{3}{|c|}{$\begin{array}{c}\text { CJT activity ( } \mathrm{ng} / \mathrm{mg} \text { of protein) } \\
\text { as determined by: }\end{array}$} & \multirow{3}{*}{$\begin{array}{c}\text { Secretion } \\
\text { in ileal } \\
\text { loops } \\
\text { (mean } V / L^{b} \\
\pm \text { SEM })^{b}\end{array}$} \\
\hline & & \multicolumn{2}{|c|}{ ELISA } & \multirow{2}{*}{$\mathrm{CHO}$} & \\
\hline & & $\mathrm{LT} / \mathrm{LT}$ & GM/LT & & \\
\hline $\mathrm{Cl}$ & 0.136 & 0 & 0 & 0 & $24 \pm 9$ \\
\hline C6 & 0.312 & 0 & 0 & 0 & $28 \pm 14$ \\
\hline C5 & 0.326 & 0.02 & 0.1 & 0.1 & $75 \pm 8$ \\
\hline $\mathrm{C} 2$ & 0.238 & 0.06 & 1.5 & 1.1 & $174 \pm 7$ \\
\hline C3 & 0.309 & 0.10 & 5.1 & 4.4 & $289 \pm 11$ \\
\hline $\mathrm{C} 4$ & 0.296 & 2.06 & 14.9 & 8.5 & $295 \pm 14$ \\
\hline INN-1-79 & 0.483 & 3.05 & 11.4 & 14.3 & $265 \pm 15$ \\
\hline INN-73-83 & 0.467 & 3.87 & 50.6 & 29.1 & $321 \pm 1$ \\
\hline
\end{tabular}

" $\mathrm{OD}_{650}$. Optical density of the broth cultures at $650 \mathrm{~nm}$.

${ }^{b} V / L$, Volume/length ratio of challenged rat ligated ileal loops. 
that produced the most CJT gave a positive response (i.e., an optical density $\geq 0.200$ ) in the LT/LT ELISA, whereas the GM/LT ELISA distinguished between CJT-producing strains and those which produced either no or a negligible quantity of toxin (Fig. 3).

Properties of CJT. The crude CJT used in these studies was obtained from 10-fold-concentrated polymyxin-treated broth supernatants of strain INN-73-83. The concentration of CJT in the three lots used varied between 29.1 and $44.7 \mathrm{ng}$ of toxin per mg of total protein as determined by the $\mathrm{CHO}$ assay; the amount of supernatant used in different studies was expressed as that of the toxin present. All lots were used within 2 weeks of preparation because, as noted by others (41), toxin activity is progressively lost after 2 weeks even in samples to which soybean trypsin inhibitor (Sigma) is added and which are stored at $-60^{\circ} \mathrm{C}$.

(i) Inhibition by GM ganglioside of $\mathrm{CJT}$ activity in $\mathrm{CHO}$ cells. From a concentration of $1,000 \mathrm{pg}$ in $25 \mu \mathrm{l}$, twofold serial dilutions of GM ganglioside were added to equal volumes containing 2.5 times the minimum amounts of toxins that gave a positive response in the $\mathrm{CHO}$ assay $(50 \mathrm{pg}$ of pure LT and $82 \mathrm{pg}$ of CJT). The smallest amount of GM ganglioside that gave a negative response in the $\mathrm{CHO}$ assay was $125 \mathrm{pg}$ for LT and $250 \mathrm{pg}$ for CJT. This indicated that the inhibitory ratio of GM ganglioside to toxin by weight was 2.5 for LT and 3.1 for CJT.

(ii) Neutralization by antiserum to LT of CJT activity in CHO cells. Twofold serial dilutions of $100 \mu$ l of goat hyperimmune antiserum to LT were incubated with $50 \mathrm{pg}$ of LT, 1 ng of CT, or $82 \mathrm{pg}$ of CJT. The antiserum dilution of the last positive well was multiplied by the amount of toxin in the sample; the value obtained was multiplied by 10 to give a per-milliliter value and then divided by 1,000 to obtain the neutralizing capacity of $1 \mathrm{ml}$ of antiserum for nanogram quantities of the toxins. A 1-ml amount of antiserum to LT neutralized $512 \mathrm{ng}$ of LT, $320 \mathrm{ng}$ of CT, and $205 \mathrm{ng}$ of CJT. In another experiment, twofold serial dilutions of purified antiserum to CT (Swiss Serum and Vaccine Institute, Bern,

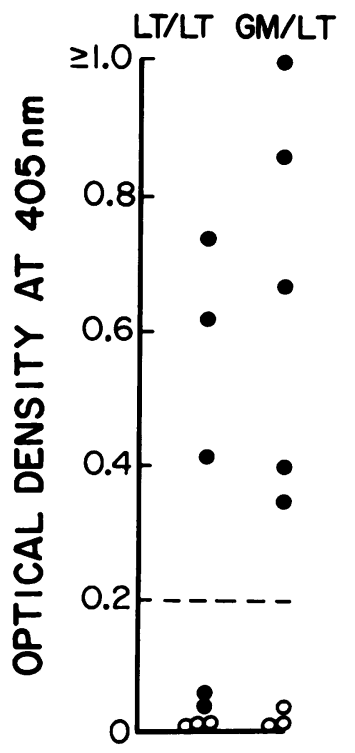

FIG. 3. Response in LT/LT and GM/LT ELISAs of unconcentrated broth supernatants of various $C$. jejuni strains. $O$, Strains with no or slight toxigenicity as determined by other quantitative assays; $\bullet$, toxigenic strains.

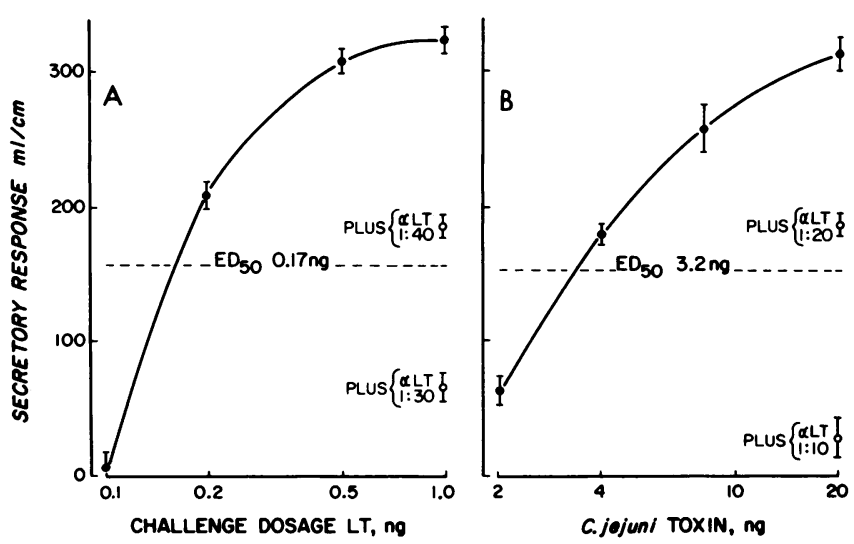

FIG. 4. Secretory response to graded doses of LT (A) and crude CJT (B) in ligated ileal loops of unimmunized rats. Values for CJT are expressed in nanograms of toxin per milligram of total protein as determined by $\mathrm{CHO}$ assay. $\mathrm{ED}_{50}$, One-half the dose which yielded maximum secretion. $\alpha \mathrm{LT}$, Response when antiserum to LT was added at the indicated dilution.

Switzerland) were mixed with the same amounts of the toxins; $1 \mathrm{ml}$ of CT antiserum neutralized 2,560 $\mathrm{ng}$ of CT, 256 ng of LT, and $205 \mathrm{ng}$ of CT.

(iii) Neutralization by antiserum to LT of the secretory effect of CJT in ligated rat ileal loops. The results for the secretory response to the instillation of graded amounts of CJT into ligated rat ileal loops was compared with a previously obtained (32) dose-response curve for pure LT (Fig. 4). CJT gave a dose-dependent response, with an $\mathrm{ED}_{50}$ (one-half the dose which yields maximum secretion) of $3.2 \mathrm{ng}$, versus 0.17 $\mathrm{ng}$ for LT. Tenfold serial dilutions of goat anti-LT antiserum in $250 \mu \mathrm{l}$ were incubated at $37^{\circ} \mathrm{C}$ for $1 \mathrm{~h}$ with $250 \mu \mathrm{l}$ containing those doses which gave maximum secretion (20 ng of CJT and $1 \mathrm{ng}$ of LT). The secretory effect of CJT was completely neutralized by an antiserum dilution of $1: 10$ and that of LT was completely neutralized by a dilution of 1:30.

(iv) Protection in rats immunized with LT or B subunit. Four unimmunized control rats and the same number of rats immunized with either LT or its B subunit were challenged simultaneously by instilling $20 \mathrm{ng}$ of CJT into their ligated ileal loops. The volume/length ratio (mean \pm standard error of the mean) in the control rats was $304 \pm 4$; the value decreased by $60 \%$, to $121 \pm 2$, in rats immunized with LT and by $49 \%$, to $156 \pm 4$, in those immunized with LT B subunit. Secretion was significantly $(P<0.001)$ lower in both immunized groups than in the control animals.

\section{DISCUSSION}

The results of this study agree with those previously reported by Ruiz-Palacios et al., which indicated that many strains of $C$. jejuni produce a heat-labile enterotoxin (41). Their finding that antiserum to CT neutralizes the secretory activity of crude CJT (41) led us to show that CJT is also immunologically related to $E$. coli $\mathrm{LT}$ toxin, which enabled us to quantitate CJT activity by expressing it as a function of the response to pure LT in ELISA and CHO assays. This quantitative approach showed that the amount of CJT produced and recovered depends on the culture conditions and recovery techniques used and that, as with LT production by different enterotoxigenic $E$. coli strains $(19,24)$, the amount of CJT produced by different $C$. jejuni clinical isolates varies widely. The failure of some laboratories to identify enterotoxin production by strains of $C$. jejuni in the past $(21,33,49)$ 
was probably due to their using suboptimal culture media and growth conditions, confining their assays to sonicated cells (which we found yielded only a small quantity of CJT), or performing assays that were not sensitive to CJT.

The role of CJT in the pathophysiology of $C$. jejuniinduced diarrhea has not yet been established, but it is tempting to speculate that the two pathogenic mechanisms now recognized, invasion and enterotoxin production, may account for the variable clinical pattern of diarrheal disease caused by this organism. It remains to be determined whether $C$. jejuni resembles $E$. coli in that some strains are nonpathogenic, whereas others have separate plasmid-induced properties of either invasiveness or enterotoxigenicity $(22,40,45)$. Strains of $C$. jejuni that produce either cytotonic or cytotoxic toxins in various tissue culture assays have been described (23). The relatively simple methods for identifying toxigenic strains of $C$. jejuni by $\mathrm{CHO}$ or GM/LT ELISA assays should facilitate future studies directed at determining whether a correlation exists between enterotoxin production and the presence of a secretory type of diarrhea and whether there is a difference in pathogenicity between strains isolated from sick and from asymptomatic children.

In addition to these and earlier (41) observations, which indicate that CJT is immunologically related to both CT and LT, our findings that CJT is active in a GM/LT ELISA and that its cytotonic effect in CHO cells is abolished by preincubation with GM ganglioside indicate that CJT shares with CT, LT, and Salmonella enterotoxin the property of attachment to this specific tissue receptor $(14,36)$; this is known to be a function of the B subunits in LT and CT (34). These observations suggest that, when purified, CJT may turn out to be part of the cholera- $E$. coli family of immunologically related heat-labile, adenylate cyclase-stimulating enterotoxins. Recent studies with purified Salmonella typhimurium enterotoxin have established its place in this group (17), and it is perhaps relevant that the initial studies with crude Salmonella enterotoxin which suggested this relationship were similar to ours with crude CJT, in that antiserum to CT neutralizes the cytotonic effect of crude Salmonella enterotoxin in CHO cells (44) and that immunization with procholeragenoid reduces the secretory effect of viable Salmonella cells in ligated ileal loops (37).

Acute diarrheal disease continues to be a major cause of morbidity and mortality among young children in developing countries (46). Of the three enteric pathogens principally responsible for acute diarrheal disease, vaccines for two, rotavirus and enterotoxigenic $E$. coli, are currently being developed $(25,31)$, but no such approach has been considered for $C$. jejuni. Should toxigenic strains of $C$. jejuni eventually prove to be a significant cause of diarrhea, then the demonstrated immunological homology between CJT and $\mathrm{LT}$ raises the possibility that toxoid vaccines containing LT or its B subunit $(27,28)$ might also provide some degree of protection against diarrhea caused by toxigenic strains of C. jejuni.

\section{ACKNOWLEDGMENTS}

We thank Helen Short for advice and assistance with the bacterial cultures.

This work was supported by a grant from Johnson \& Johnson, New Brunswick, N.J.

\section{LITERATURE CITED}

1. Black, R. E., M. H. Merson, I. Huq, A. R. M. A. Alim, and M. Yunus. 1981. Incidence and severity of rotavirus and Escherichia coli diarrhoea in rural Bangladesh: implications for vaccine development. Lancet i:141-143.

2. Blaser, M. J., I. D. Berkowitz, F. M. LaForce, J. Cravens, L. B. Reller, and W.-L. L. Want. 1979. Campylobacter enteritis: clinical and epidemiologic features. Ann. Intern. Med. 91:179185.

3. Blaser, M. J., R. I. Glass, M. I. Huq, B. Stoll, G. M. Kibriya, and A. R. M. A. Alim. 1980. Isolation of Campylobacter fetus subsp. jejuni from Bangladeshi children. J. Clin. Microbiol. 12:744-747.

4. Blaser, M. J., and L. B. Reller. 1981. Campylobacter enteritis. N. Engl. J. Med. 305:1444-1452.

5. Bokkenheuser, V. D., N. J. Richardson, J. H. Bryner, D. J. Roux, A. B. Schutte, H. J. Koornhof, I. Freiman, and E. Hartman. 1979. Detection of enteric campylobacteriosis in children. J. Clin. Microbiol. 9:227-232.

6. Branski, D., D. Roll, E. Gross-Kieselstein, V. Gross, L. Greenberg, and A. Abrahamov. 1982. Campylobacter enteritis in infants and young children. Isr. J. Med. Sci. 18:615-617.

7. Caldwell, M. B., R. I. Walker, S. D. Stewart, and J. E. Rogers. 1983. Simple adult rabbit model for Campylobacter jejuni enteritis. Infect. Immun. 42:1176-1182.

8. Caprioli, A., V. Falbo, L. G. Roda, F. M. Ruggeri, and C. Zona. 1983. Partial purification and characterization of an Escherichia coli toxic factor that induces morphological cell alterations. Infect. Immun. 39:1300-1306.

9. Clements, J. D., and R. A. Finkelstein. 1979. Isolation and characterization of homogeneous heat-labile enterotoxins with high specific activity from Escherichia coli cultures. Infect. Immun. 24:760-769.

10. Clements, J. D., D. C. Flint, R. F. Engert, and F. A. Klipstein. 1983. Cloning and molecular characterization of the $\mathbf{B}$ subunit of Escherichia coli heat-labile enterotoxin. Infect. Immun. 40:653658.

11. Clements, J. D., D. C. Flint, and F. A. Klipstein. 1982. Immunological and physicochemical characterization of heat-labile enterotoxins isolated from two strains of Escherichia coli. Infect. Immun. 38:806-809.

12. Clements, J. D., R. J. Yancey, and R. A. Finkelstein. 1980. Properties of homogeneous heat-labile enterotoxin from Escherichia coli. Infect. Immun. 29:91-97.

13. DeMol, P., and E. Bosmans. 1978. Campylobacter enteritis in Central Africa. Lancet i:604.

14. Donta, S. T., and J. P. Viner. 1975. Inhibition of the steroidogenic effects of cholera and heat-labile Escherichia coli enterotoxins by GM, ganglioside: evidence for a similar receptor site for the two toxins. Infect. Immun. 11:982-985.

15. Drake, A. A., M. J. R. Gilchrist, J. A. Washington, K. A. Huizenga, and R. E. VanScoy. 1981. Diarrhea due to Campylobacter fetus subspecies jejuni. A clinical review of 63 cases. Mayo Clin. Proc. 56:414-423.

16. Fernández, H., U. F. Neto, F. Fernandes, M. de Almeida Pedra, and L. R. Trabulsi. 1983. Culture supernatants of Campylobacter jejuni induce a secretory response in jejunal segments of adult rats. Infect. Immun. 40:429-431.

17. Finkelstein, R. A., B. A. Marchlewicz, R. J. McDonald, and M. Boesman-Finkelstein. 1983. Isolation and characterization of a cholera-related enterotoxin from Salmonella typhimurium. FEMS Microbiol. Lett. 17:239-241.

18. Glass, R. I., B. J. Stoll, M. I. Huq, M. J. Struelens, M. Blaser, and A. K. M. G. Kibriya. 1983. Epidemiologic and clinical features of endemic Campylobacter jejuni infection in Bangladesh. J. Infect. Dis. 148:292-296.

19. Greenberg, H. B., D. A. Sack, W. Rodriguez, R. B. Sack, R. G. Wyatt, A. R. Kalica, R. L. Horswood, R. M. Chanock, and A. Z. Kapikian. 1977. Microtiter solid-phase radioimmunoassay for detection of Escherichia coli heat-labile enterotoxin. Infect. Immun. 17:541-545.

20. Guerrant, R. L., L. L. Brunton, T. C. Shnaitman, L. I. Rebhun, and A. G. Gilman. 1974. Cyclic adenosine monophosphate and alteration of Chinese hamster ovary cell morphology: a rapid, sensitive in vitro assay for the enterotoxins of Vibrio cholerae and Escherichia coli. Infect. Immun. 10:320-327.

21. Guerrant, R. L., R. G. Lahita, W. C. Winn, and R. B. Roberts. 
1978. Campylobacteriosis in man: pathogenic mechanisms and review of 91 bloodstream infections. Am. J. Med. 65:584-592.

22. Harris, J. R., I. K. Wachsmuth, B. R. Davis, and M. L. Cohen. 1982. High-molecular-weight plasmid correlates with Escherichia coli enteroinvasiveness. Infect. Immun. 37:1295-1298.

23. Johnson, W. M., and H. Lior. 1984. Toxins produced by Campylobacter jejuni and Campylobacter coli. Lancet i:229230.

24. Kantor, H. S., P. Tao, and S. L. Gorbach. 1974. Stimulation of intestinal adenyl cyclase by Escherichia coli enterotoxin: comparison of strains from an infant and an adult with diarrhea. J. Infect. Dis. 129:1-9.

25. Kapikian, A. Z., R. G. Wyatt, H. B. Greenberg, A. R. Kalica, H. W. Kim, C. D. Brandt, W. J. Rodriguez, R. H. Parrott, and R. M. Chanock. 1980. Approaches to immunization of infants and young children against gastroenteritis due to rotavirus. Rev. Infect. Dis. 2:459-469.

26. Klipstein, F. A., and R. F. Engert. 1981. Protective effect of immunization of rats with holotoxin or B subunit of Escherichia coli heat-labile enterotoxin. Infect. Immun. 31:144-150.

27. Klipstein, F. A., R. F. Engert, J. D. Clements, and R. A. Houghten. 1983. Vaccine for enterotoxigenic Escherichia coli based on synthetic heat-stable toxin cross-linked to the B subunit of heat-labile toxin. J. Infect. Dis. 147:318-326.

28. Klipstein, F. A., R. F. Engert, and R. A. Houghten. 1983. Protection in rabbits immunized with a vaccine of Escherichia coli heat-stable toxin cross-linked to the heat-labile toxin B subunit. Infect. Immun. 40:888-893.

29. Klipstein, F. A., R. F. Engert, R. A. Houghten, and B. Rowe. 1984. Enzyme-linked immunosorbent assay for Escherichia coli heat-stable enterotoxin. J. Clin. Microbiol. 19:798-803.

30. Lambert, M. E., P. F. Schofield, A. G. Ironside, and B. K. Mandal. 1979. Campylobacter colitis. Br. Med. J. 1:857-859.

31. Levine, M. M., J. B. Kaper, R. E. Black, and M. L. Clements. 1983. New knowledge on pathogenesis of bacterial enteric infections as applied to vaccine development. Microbiol. Rev. 47:510-550.

32. Lowry, O. H., N. J. Rosenbrough, A. L. Farr, and R. J. Randall. 1951. Protein measurement with the Folin phenol reagent. J. Biol. Chem. 193:265-275.

33. Manninen, K. I., J. F. Prescott, and I. R. Dohoo. 1982. Pathogenicity of Campylobacter jejuni isolates from animals and humans. Infect. Immun. 38:46-52.

34. Osborne, J. C., Jr., J. Moss, P. H. Fishman, S. Nakaya, and D. C. Robertson. 1982. Specificity in protein-membrane associations: the interaction of gangliosides with Escherichia coli heatlabile enterotoxin and choleragen. Biophys. J. 37:168-169.
35. Pai, C. H., S. Sorger, L. Lackman, R. E. Sinai, and M. I. Marks. 1979. Campylobacter gastroenteritis in children. J. Pediatr. 94:589-591.

36. Peterson, J. W. 1980. Salmonella toxin. Pharmacol. Ther. 11:719-724.

37. Peterson, J. W., and P. D. Sandefur. 1979. Evidence of a role for permeability factors in the pathogenesis of salmonellosis. Am. J. Clin. Nutr. 32:197-209.

38. Pitkänen, T. 1982. Travellers' diarrhoea caused by Campylobacter jejuni. Ann. Clin. Res. 14:111-113.

39. Rajan, D. P., and V. I. Mathan. 1982. Prevalence of Campylobacter fetus subsp. jejuni in healthy populations in southern India. J. Clin. Microbiol. 15:749-751.

40. Rowe, B. 1979. The role of Escherichia coli in gastroenteritis Clin. Gastroenterol. 8:625-644.

41. Ruiz-Palacios, G. M., J. Torres, N. I. Torres, E. Escamilla, B. R. Ruiz-Palacios, and J. Tamayo. 1983. Cholera-like enterotoxin produced by Campylobacter jejuni. Lancet ii:250-253.

42. Ryder, R. W., C. A. Oquist, H. Greenberg, D. N. Taylor, F. Ørskov, I. Ørskov, A. Z. Kapikian, and R. B. Sack. 1981. Travelers' diarrhea in Panamanian tourists in Mexico. J. Infect. Dis. 144:442-448.

43. Ryder, R. W., D. A. Sack, A. Z. Kapikian, J. C. McLaughlin, J. Chakraborty, A. S. M. M. Rahman, M. H. Merson, and J. G. Wells. 1976. Enterotoxigenic Escherichia coli and reovirus-like agent in rural Bangladesh. Lancet i:659-662.

44. Sandefur, P. D., and J. W. Peterson. 1977. Neutralization of Salmonella toxin-induced elongation of Chinese hamster ovary cells by cholera antitoxin. Infect. Immun. 15:988-992.

45. Smith, H. R., S. M. Scotland, and B. Rowe. 1983. Plasmids that code for production of colonization factor antigen II and enterotoxin production in strains of Escherichia coli. Infect. Immun. 40:1236-1239.

46. Snyder, J. D., and M. H. Merson. 1982. The magnitude of the global problem of acute diarrhoeal disease: a review of active surveillance data. Bull. W.H.O. 60:605-613.

47. Speelman, P., M. J. Struelens, S. C. Sanyal, and R. I. Glass. 1983. Detection of Campylobacter jejuni and other potential pathogens in travellers' diarrhoea in Bangladesh. Scand. J. Gastroenterol. 18(Suppl. 84):19-23.

48. Svedhem, Å., and B. Jaijser. 1980. Campylobacter fetus subspecies jejuni: a common cause of diarrhea in Sweden. J. Infect. Dis. 142:353-359.

49. Wadström, T., S. B. Baloda, K. Drovacek, A. Faris, S. Bengston, and M. Walder. 1983. Swedish isolates of Campylobacter jejunil coli do not produce cytotonic or cytotoxic enterotoxins. Lancet ii:911. 